2. Paraskevas $\mathrm{Kl}$, Bessias N, Perdikides TP, Mikhailidis DP. Statins and venous thromboembolism: A novel effect of statins? Current Medical Research and Opinion 2009; 25(7):1807-09. http://dx.doi.org/10.1185/03007990903052591

3. Waters DD. Exploring new indications for statins beyond atherosclerosis: Successes and setbacks. J Cardiol 2010;55(2):155-62.

http://dx.doi.org/10.1016/j.jjcc.2009.12.003

4. Muscal E, Brey RL Antiphospholipid syndrome and the brain in pediatric and adult patients. Lupus 2010;19(4):406-11. http://dx.doi.org/10.1177/0961203309360808

5. Pedersen TR. Pleiotropic effects of statins: evidence against benefits beyond LDLcholesterol lowering. Am J Cardiovasc Drugs 2010;10(Suppl 10).

6. Morales-Villegas EC, Di Sciascio G, Briguori C. Statins: Cardiovascular Risk Reduction in Percutaneous Coronary Intervention-Basic and Clinical Evidence of Hyperacute Use of Statins. Int J Hypertens 2011;904742.

7. Wald DS, Wald NJ. The Polypill in the prevention of cardiovascular disease. Prev Med 2011;52(1):16-17. http://dx.doi.org/10.1016/j.ypmed.2010.11.015

8. Dark J, Corris PA. Lung Transplantation in Respiratory Medicine. Eds Gibson J, Geddes D, Costabel U et al. Saunders, London 2003 pp496

9. Schwab JM, Nguyen TD, Meyermann R, Schluesener HJ. Human focal cerebral infarctions induce differential lesional interleukin-16 (IL-16) expression confined to infiltrating granulocytes, CD8+ T-lymphocytes and activated microglia/macrophages. Journal of Neuroimmunology 2001;114:232-24. http://dx.doi.org/10.1016/S0165-5728(00)00433-1

10. Heart Stabile E, Kinnaird T, la Sala A, et al. CD8+ T Lymphocytes Regulate the Arteriogenic Response to Ischemia by Infiltrating the Site of Collateral Vesse Development and Recruiting CD4 Mononuclear Cells Through the Expression of Interleukin-16. Circulation 2006,113:118-24 http://dx.doi.org/10.1161/CIRCULATIONAHA.105.576702

11. National Research Council. "10 Tobacco Smoke and Toxicology." Clearing the Smoke: Assessing the Science Base for Tobacco Harm Reduction. Washington, DC: The National Academies Press, 2001.)

12. McDonough JE, Yuan R, Suzuki M. Small-Airway Obstruction and Emphysema in Chronic Obstructive Pulmonary Disease. N Engl J Med 2011;365:1567-75. http://dx.doi.org/10.1056/NEJMoa1106955

13. Schwartz J. A spine for our time. Thorax 2011;66:841-2

http://dx.doi.org/10.1136/thx.2010.154195

\title{
Oral immunotherapy for peanut allergy: an evidence-based medicine assessment
}

\section{See linked article by Sheikh et al. on pg 41}

\section{*Jan Lötvalla, Moisés A Calderón ${ }^{b}$}

a Professor of Clinical Allergy, Krefting Research Centre, University of Gothenburg, Göteborg, Sweden

a Section of Allergy and Clinical Immunology, Imperial College National Heart and Lung Institute, Royal Brompton Hospital, London, UK

*Correspondence: Professor Jan Lötvall, Professor of Clinical Allergy, Krefting Research Centre, University of Gothenburg, BOX 424, SE 40530 Göteborg, Sweden Tel: + 46317866717 Fax: +4631786 6730 E-mail: jan.lotvall@gu.se

Food-induced allergic disorders mediated by IgE represent a major health problem, affecting children and adults worldwide.' Even though the exact prevalence of food allergy is difficult to determine, it has been reported that in some countries IgE-mediated food allergy affects up to $6-8 \%$ of children and up to $2-4 \%$ of adults. ${ }^{1-3}$ Some food allergies such as egg, milk, soy and wheat may be outgrown within the first decade of life, whilst others such as peanut, tree nuts, fish and shellfish are often lifelong. ${ }^{4}$ Food allergy has different clinical manifestations involving many body systems including the skin, the gastrointestinal and respiratory tracts, and the cardiovascular system. Furthermore, the incidence of food-related anaphylaxis primarily in children seems to be increasing globally. Individuals with both severe or difficult asthma and a history of food allergy are those at highest risk of developing life-threatening anaphylactic reactions.

One of the major food allergens in many countries is peanut. ${ }^{5,6}$
Peanuts are widely used as a nutritious oral aliment (providing protein, vitamins and minerals) and are the most common food-related cause of IgE-mediated allergic reactions. ${ }^{7}$ Patients with atopic dermatitis can increase their risk to sensitisation to peanuts and subsequently the development of peanut allergy due to cutaneous exposure to peanut oil-containing creams. ${ }^{8}$ Reactions to peanuts are immediate and can be severe, even life-threatening. Symptoms range from a relatively mild urticarial rash, vomiting, diarrhoea, wheezing, and dyspnoea, to severe throat angioedema, cardiovascular collapse or fulminant anaphylaxis. ${ }^{9}$ Patients with well-documented peanut allergy often have to carry rescue medication such as adrenaline auto-injectors to treat themselves if severe reactions occur. ${ }^{9}$ Measures to prevent (or even cure) food allergies such as peanut allergy are therefore a high scientific priority in the field of allergic disease, and many attempts to induce tolerance to peanut are under way.

In this issue of the Primary Care Respiratory Journal, Sheikh and colleagues present a timely systematic review ${ }^{10}$ of studies that have attempted to induce desensitisation and tolerance to peanut by oral immunotherapy in patients with such allergy. A thorough search of the major biomedical databases was conducted using a previously designed study protocol. In total, 1,672 potentially eligible studies were identified. After a systematic evaluation, only six studies met the study inclusion criteria, enrolling 85 patients in total. Surprisingly, the duration of oral immunotherapy treatment varied between studies, ranging from 6 days to 36 months. Four studies were multicentre and two single centre. Four studies were conducted in the USA and two in Europe. All studies used a "case series" design, and so this systematic review lacks the strength that can be provided by randomised prospective placebo-controlled studies. This situation was stated by the authors to be at high risk of bias. Regardless, the studies overall argue that oral immunotherapy may have some future, since the treated patients tolerated higher doses of peanut after the 
immunotherapy treatment. This could be a promising new therapeutic intervention for the short- to medium-term management of well selected patients. It is stated that this treatment should always be given in clinical settings and patients should be monitored carefully.

The authors wisely conclude ${ }^{10}$ that the science suggests that this approach has indeed potential, but many obstacles remain. So far, immunotherapy for food allergens, including peanut, is an experimental therapy in specialist centres. Robust evidence-based medicine data is required.

It is important to consider that in order to achieve successful results in terms of tolerance and desensitisation after using allergen specific immunotherapy, the dose of allergen given to the patient should be at high doses. This implies an innate risk of inducing severe systemic adverse reactions including anaphylaxis. Therefore, in some specific cases such as asthmatic patients with peanut allergy, it may be worth evaluating the use of anti-lgE therapy as combination treatment with allergen immunotherapy. This may allow higher doses of immunotherapy to be achieved more rapidly in a safe manner.

Oral immunotherapy for food allergy is a new approach in the treatment of allergic diseases. This systematic review ${ }^{10}$ shows the urgent need in the field of food allergy to conduct well-designed and well-powered studies using proper standardised allergens. Serious attention should be focused on various methodological issues including:

(i) the selection of patients

(ii) the design of the studies

(iii) the selection of validated outcomes for the evaluation of effectiveness

(iv) the statistical analyses

(v) the duration of treatment, and

(vi) the evaluation of safety.
Due to the nature of food allergies, future cost-effective studies are mandatory.

Conflicts of interest The authors declare that there are no conflicts of interest in relation to this article.

Commissioned article; not externally peer-reviewed; accepted 26th January 2012 ; online 23rd February 2012

(C) 2012 Primary Care Respiratory Society UK. All rights reserved http://dx.doi.org/10.4104/pcrj.2012.00019 Prim Care Respir J 2012; 21(1): 7-8

\section{References}

1. Wasserman S and Watson W. Food Allergy. Allergy, Asthma \& Clin Immunol 2011 ; 7(Suppl 1):1-7.

2. Zuidmeer L, Goldhahn K, Rona RJ, et al. The prevalence of plant food allergies: $A$ systematic review. J Allergy Clin Immunol 2008;121:1210-18.

3. Sicherer SH, Sampson HA. Food allergy. J Allergy Clin Immunol 2010;125(2 Suppl 2):S116-25

4. Wood RA. The natural history of food allergy. Pediatrics 2003;111(6 pt 3):1631-7.

5. Rona RJ, Keil T, Summers $C$, et al. The prevalence of food allergy: a meta-analysis. J Allergy Clin Immunol 2007;120:638-46.

6. Kotz D, Simpson CR, Sheikh A. Incidence, prevalence, and trends of general practitioner-recorded diagnosis of peanut allergy in England, 2001 to 2005 . Allergy Clin Immunol 2011;127:623-30.

7. Sicherer SH. Clinical update on peanut allergy. Ann Allergy Asthma Immunol 2002; 88:350-61.

8. Lack G, Fox D, Northstone K, Golding J. Avon Longitudinal Study of Parents and Children Study Team. Factors associated with the development of peanut allergy in childhood. N Engl J Med 2003;348(11):977-85

9. Simons FE, Ardusso LR, Bilò MB, et al. World Allergy Organization anaphylaxis guidelines: summary. J Allergy Clin Immunol 2011;127(3):587-93.

10. Sheikh A, Nurmatov $U$, Venderbosch I, BischoffE. Oral immunotherapy for the treatment of peanut allergy: systematic review of six case series studies. Prim Care Respir J 2011;21:41-49. http://dx.doi.org/10.4104/pcrj.2011.00071

\section{Single inhaler maintenance and reliever therapy (SMART) in general practice asthma management: where are we?}

\section{See linked article by Riemersma et al. on pg 50}

\section{*Mike Thomas ${ }^{\mathrm{a}}$, Ian Pavord}

a GP Michinhampton, Gloucs UK; Professor of Primary Care Research, University of Southampton, Southampton, UK

b Consultant Physician and Honorary Professor of Medicine Department of Respiratory Medicine, Thoracic Surgery and Allergy, University Hospitals of Leicester NHS Trust, Glenfield Hospital, Leicester

*Correspondence: Professor Mike Thomas, Professor of Primary Care Research, University of Southampton, Aldermoor Health Centre, Aldermoor Close, Southampton, SO16 5ST, UK Tel: +44 (0)23 80241050 Fax: +44 (0)23 80701125

E-mail: drmike.thomas@btinternet.com
Despite effective pharmacological options for treating asthma, most patients fail to achieve good control. ${ }^{1}$ Non-adherence is common, with over-reliance on short-acting $\beta_{2}$-agonists (SABA) and under-use of inhaled corticosteroids (ICS) frequently being observed. ${ }^{2}$ There is a real need to consider new approaches to improve outcomes.

One approach that has attracted attention and controversy is Single inhaler Maintenance And Reliever Therapy (SMART) using the budesonide-formoterol combination inhaler Symbicort ${ }^{\mathrm{TM}}$. SMART is advocated by proponents on both pragmatic and theoretical grounds, ${ }^{3}$ and its use in primary care is addressed by Riemersma et al. in this issue of the $P C R J{ }^{4}$

In the traditional 'step-wise' asthma guideline model, therapy classes are added and doses increased when control is not achieved. Most patients use regular ICS 'preventer' treatment and an additional SABA inhaler used on an 'as-needed' basis; but when patients remain uncontrolled on ICS, long-acting $\beta_{2}$-agonist (LABA) treatment is added, increasingly in the form of a fixed-dose ICS/LABA combination 